\title{
In Vitro Evaluation of the Abrasiveness of Novel Bioactive Glass Powders (BiominF®) on Ivory Dentine in Air Polishing Procedures Compared to Selected Reference Powders
}

\author{
Kitichai Janaphan ${ }^{1,3}$, Robert G. Hill ${ }^{1}$ and David G Gillam ${ }^{2}$ \\ ${ }^{1}$ Dental Physical Sciences, Barts and the London School of Medicine and Dentistry, Institute of Dentistry, Queen Mary University of London, Mile End \\ Road, London E1 4NS, UK \\ ${ }^{2}$ Centre for Oral Bioengineering, Institute of Dentistry, Barts and the London School of Medicine and Dentistry QMUL, London EA1 2AD, UK \\ ${ }^{3}$ Department of Periodontics \& Implant Dentistry, Faculty of Dentistry, Thammasat University, Patum Thani 12120, Thailand
}

${ }^{*}$ Corresponding author: Dr David G Gillam, Centre for Oral Bioengineering Institute of Dentistry Barts and the London School of Medicine and Dentistry QMUL, London EA1 2AD, UK; E-mail: d.g.gillam@qmul.ac.uk

Received: November 23, 2021; Accepted: November 29, 2021; Published: November 30, 2021

\begin{abstract}
Objectives: To evaluate the abrasiveness of novel Bioactive Glass Powders (BiominF ${ }^{\circledR}$ ) on Ivory Dentine compared to selected reference powders.

Materials and Methods: Ivory dentine was used as the study sample. Bioactive glasses (Biomin $\mathrm{F}^{\circledR}$ and Sylc ${ }^{\circledR}$ Blend) was compared with sodium bicarbonate, glycine, erythritol powders. Particle size analysis and powder output rate were undertaken. The powders were applied for 5 and 10 s in a standardized procedure. Evaluation of wear depth on dentine in $\mu \mathrm{m}$ was assessed using White Light Profilometry.
\end{abstract}

Results: BiominF ${ }^{\circledR}$, Glycine, and erythritol powders showed similar powder output rates. Bioactive glasses (BiominF ${ }^{\circledR}$ and Sylc ${ }^{\circledR}$ Blend) resulted in significantly deeper wear depth compared to references powders. There were no significant differences in wear depth between sodium bicarbonate, glycine, and erythritol powders.

Conclusions: Bioactive glasses (BiominF ${ }^{\circledR}$ and Sylc ${ }^{\circledR}$ Blend) were significant more abrasive than sodium bicarbonate, glycine, and erythritol powders.

Clinical Relevance: Application of bioactive glasses powder on the root surface should be used with caution despite the desensitizing effect and the promotion of remineralization.

Keywords: Bioactive glass, Air-polishing, Sodium bicarbonate, Glycine, Erytritol, Subgingival root debridement, Ivory dentine, Particle size analysis, White light profilometry

\section{Introduction}

Periodontitis is defined as a chronic multifactorial inflammatory disease associated with dysbiosis plaque biofilms and characterized by progressive destruction of tooth-supporting apparatus [1]. The control of the dental biofilm remains the cornerstone for periodontal treatment and the prevention of disease recurrence during supportive periodontal care (SPC). The repeated instrumentation by conventional techniques (hand curettes and/or ultrasonic instruments) may cause some degree of tooth structure loss which increases patient discomfort and dentine hypersensitivity [2,3]. An air-polishing device has been introduced as an alternative method to remove the dental biofilm. Several clinical studies have demonstrated that the application of air-polishing could result in similar outcomes in biofilm removal as well as in clinical parameters with less discomfort and operator time compared to conventional methods [4-6]. Recently, the application of air-polishing has been extended to surface decontamination during periodontal surgery [7].
Different powders are being used for periodontal treatment including; sodium bicarbonate, glycine, erythritol, and recently, bioactive glasses powders. Glycine powder has been shown to be less invasive to both root cementum and dentine compared to sodium bicarbonate as well as providing an equally effective biofilm removal $[8,9]$. The application of glycine powder resulted in less patient discomfort compared to hand instrumentation [10]. It was concluded that glycine powder may be safely applied to root surfaces and gingiva [11]. Erythritol was shown to be safe when used for subgingival application and achieved similar clinical outcomes in periodontal pocket reduction compared to ultrasonic debridement [6].

Bioactive glasses have been introduced for air-polishing applications. The main benefit is the ability of these powders to react with oral fluid leading to the formation of apatite to occlude dentinal tubules. The occlusion of these powders could reduce dentinal hypersensitivity and improved patient comfort during periodontal treatment. The application of bioactive glasses in the air-polishing 
procedure resulted in the reduction of dentine permeability by creating dentine surfaces that are more resistant to acid attack [12]. It has been confirmed in a clinical study that using bioactive glasses for airpolishing applications offered additional effects with a desensitizing effect and better patient acceptance [13]. BiominF ${ }^{\circ}$ is a novel bioactive glass that contains fluorine in addition to calcium and phosphate which results in the precipitation of a more acid-resistant fluorapatite. A previous study showed that this powder is more conservative than both sodium bicarbonate and glycine powder as well as demonstrating tubular occlusion on the dentinal tubules [14].

A direct comparison between currently available polishing powders using in a standardized method is still lacking. Thus, the aim of the study was to evaluate the abrasiveness of novel bioactive glass powders $\left(\right.$ BiominF $\left.^{\circ}\right)$ on ivory dentine compare to the reference powders. The null hypothesis would be that all polishing powders will result in no statistically change in dentine loss.

\section{Materials and Methods}

\section{Sample Size Preparation}

Ivory dentine obtained from UK airport customs which was delivered to Queen Mary University of London for research purposes $y$ and used as the study sample. The dentine was sectioned with a hacksaw to obtain $15 \mathrm{~mm}$ thick section of flat surfaces. The outer layer of the cementum was removed. The samples were polished using a Kemet 3000 LVAC (Kamet International Ltd, Maidstone, Kent, UK) with polishing discs incrementally from 360 Grits up to 4000 Grit. 1 $\mathrm{cm} \times 1 \mathrm{~cm}$ area was demarcated for the tested area for each sample. The samples were stored in an airtight container prior to use.

\section{Powder Preparation}

BiominF bioactive glass (Biomin Technology Ltd, London) was mixed with $1 \%$ by weight Aerosil ${ }^{\oplus} \mathrm{R} 974$ with Turbula ${ }^{\oplus}$ T2F shaker mixer (WAB, Switzerland) at a speed of $101 \mathrm{rpm}$ for 30 minutes to improve the flowability of the powder. References powders include Sylc Blend bioactive glass (Osspray Ltd., London, UK), AIRflow CLASSIC powder; Sodium bicarbonate (EMS Corp., Nyon, Switzerland), AIR-flow PERIO powder; Glycine (EMS Corp., Nyon, Switzerland), and AIR-flow PLUS powder; Erythritol (EMS Corp., Nyon, Switzerland) were used as supplied.

\section{Particle Size Analysis}

All tested powders were analyzed using a Malvern/E MASTERSIZER 3000 (Malvern instruments, UK). Five measurements were taken of each powder and the results were expressed as percentiles D (10), D (50), and D (90).

\section{Powder Output Test}

To determine the powder output rate of each powder in grams per minute, the NSK's Prophy-Mate neo handpiece (Nakanishi INC., Japan) was used with the air pressure set at $0.4 \mathrm{MPa}$ (58.0151 psi) for $120 \mathrm{~s}$ without application of water. The powder was checked and filled with $11 \mathrm{~g}$ of each tested powder. The powder in the chamber was weighed before and after the application using a Metteler HK160 digital scale (Mettler Toledo, UK) with an accuracy of $0.0001 \mathrm{~g}$. The measurement of each powder was repeated 5 times.

\section{Air-Polishing Test}

A Prophy-Mate neo polishing system from NSK (Nakanishi INC., Japan) was used in the experiment. The standardized protocol was followed with a distance of $5 \mathrm{~mm}$ at 90 degrees from the surface, and the air pressure was set at $0.4 \mathrm{MPa}$ (58.0151 psi). The powder chamber was checked and filled to the same level before the application without any water. Each test powder was applied for 5 and 10 seconds.

\section{White Light Profilometer Analysis}

A non-contact white light profilometry (Proscan ${ }^{\circledR} 2000$, Scantron, Taunton, UK) was used to quantify the surface loss due to the airpolishing application. A S13/1.2 chromatic sensor with $25 \mathrm{~nm}$ vertical resolution was used. A dark reference background was checked prior to scanning to ensure optimum sensitivity. An area of $3.5 \times 3.5-\mathrm{mm}$ dimension was scanned for each sample. Scanning was performed with a step size of $20 \mu \mathrm{m}$. Proscan 2000 ver. 2.1.1.8+ (Scantron industrial products Ltd, Taunton, UK) was used to quantify surface loss. The software generated three-dimensional images combining the height of focus points with the location in $\mathrm{x}$-axis and $\mathrm{y}$-axis linear position. The depth evaluation was performed by calculating the changes in $\mathrm{z}$-axis relative to unaffected reference points. Five random depth of wear areas were chosen for each sample for the depth evaluation.

\section{Statistical Analysis}

The mean wear depth and standard deviation of each group were calculated. To test for differences between groups, one-way ANOVA was performed followed by a Tukey's post hoc test. The independent samples t-test was used to compare means of wear depth between $5 \mathrm{~s}$ and $10 \mathrm{~s}$ application time. The level of significance was set at 0.05 . All statistical analysis was performed using IBM SPSS statistical software package (version 27.0 Inc., New York, NY, USA).

\section{Results}

\section{Particle Size Analysis}

The particle size distribution (in micrometers; $\mu \mathrm{m}$ ) of all powders is shown in Table 1. The numerical values are shown as percentiles of D10, D50, and D90, indicating the portion of particles with diameters below this value in $\mu \mathrm{m}$ is $10 \%, 50 \%$, and $90 \%$, respectively.

Table 1: Particle size distribution of all tested powders.

\begin{tabular}{|l|c|c|c|}
\hline Powders & \multicolumn{3}{|c|}{ Particle size $(\boldsymbol{\mu m})$} \\
\hline & D10 & D50 & D90 \\
\hline BiominF & 2.86 & 13.2 & 39.4 \\
\hline Sylc Blend & 11.7 & 52.1 & 113 \\
\hline Sodium bicarbonate & 12.5 & 49.4 & 120 \\
\hline Glycine & 5.99 & 21.3 & 51.5 \\
\hline Erythritol & 5.1 & 17.6 & 38.2 \\
\hline
\end{tabular}




\section{Powder Output Rate}

The mean \pm standard deviations of all powders are presented in Figure 1. The mean weight of powder output is presented in Figure 1. One-way ANOVA indicated there was a significant difference in power output rate between powders $(\mathrm{p}<0.001)$. A Tukey's post hoc test showed that there were statistically significant differences between the Sylc blend and sodium bicarbonate powders compared to the remaining powders $(\mathrm{p}<0.05)$. No significant differences were detected between BiominF $F^{\infty}$, glycine, and erythritol powders $(\mathrm{p}>0.05)$.

\section{White Light Profilometer Analysis}

The mean wear depth of BiominF ${ }^{\circ}$, Sylc Blend, sodium bicarbonate, glycine, and erythritol in $5 \mathrm{~s}$ and 10 s application time is presented in Figure 2. There were statistically significant differences between groups as determined by one-way ANOVA $(\mathrm{p}<0.001)$ for both application times. Overall, the wear depth of bioactive glass powders (BiominF ${ }^{\bullet}$ and Sylc blend) were significantly higher than reference powders (sodium bicarbonate, glycine, and erythritol ( $\mathrm{p}<$ 0.05) for both application times. A Tukey's post hoc test revealed deeper wear depth in both BiominF ${ }^{\circ}$ and Sylc ${ }^{\circledR}$ Blend powders compared to the other powders for both application times. The mean wear depth of BiominF ${ }^{\circ}$ was significantly higher than Sylc Blend after $5 \mathrm{~s}$ application, but not for the $10 \mathrm{~s}$ application. There were no significance differences between sodium bicarbonate and glycine, sodium bicarbonate and erythritol, and erythritol and glycine in both application times. The $10 \mathrm{~s}$ application time resulted in statistically significant deeper wear depth in BiominF $F^{\circ}$, Sylc Blend, and glycine powders $(\mathrm{p}<0.05)$. Representative profilometer scanned surfaces of ivory dentine are shown in Figure 3 after air-polishing with the powders for $5 \mathrm{~s}$ and $10 \mathrm{~s}$.

In summary, the null hypothesis was rejected, bioactive glass powders resulted in greater wear depth compared to the reference powders.

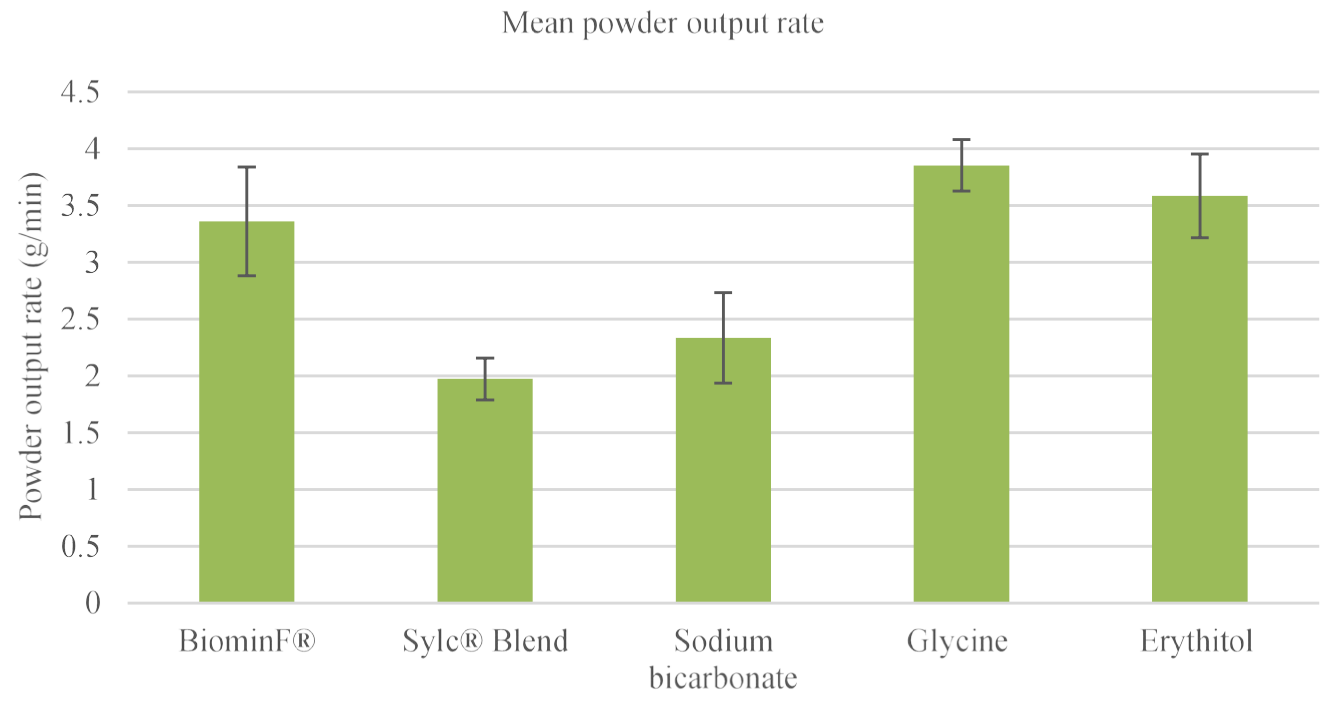

Figure 1: Comparison of the mean powder output rate \pm SD between different powders.

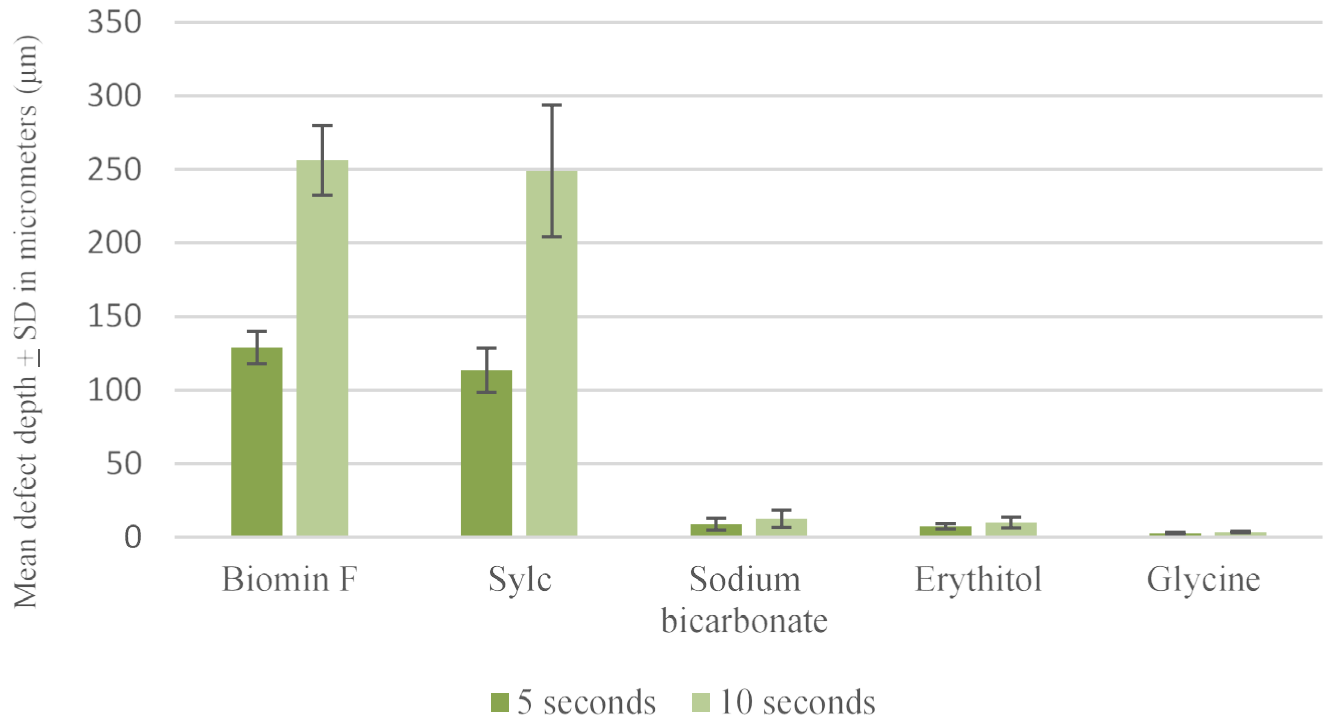

Figure 2: Mean wear depth in micrometers $(\mu \mathrm{m})$ of the different powders for $5 \mathrm{~s}$ and $10 \mathrm{~s}$ application time. 
a)

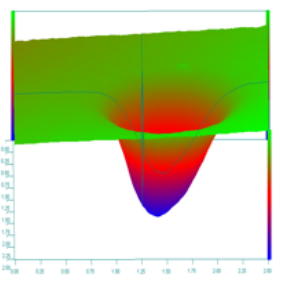

$5 \mathrm{~s}$

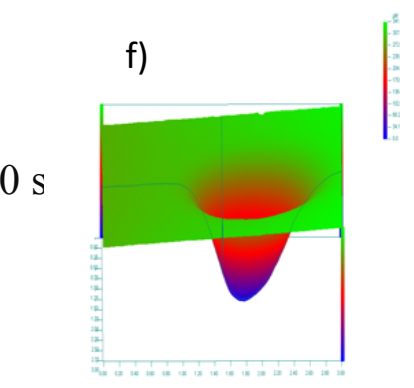

b)

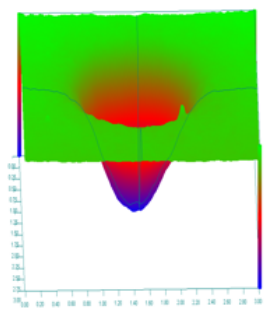

g)

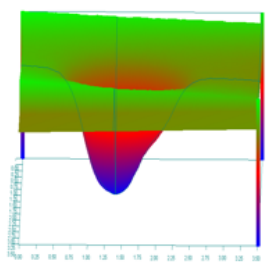

c)

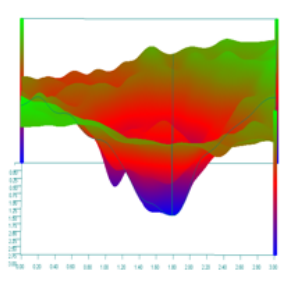

h)

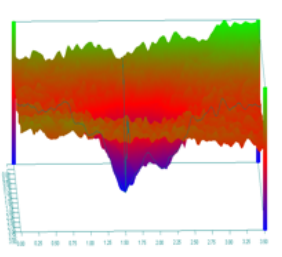

d)

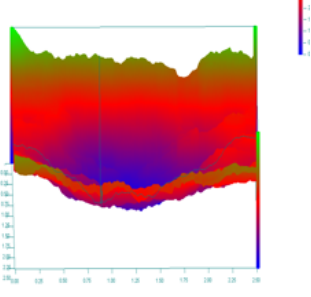

i)

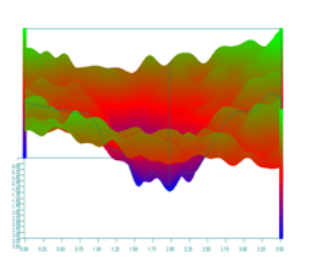

e)

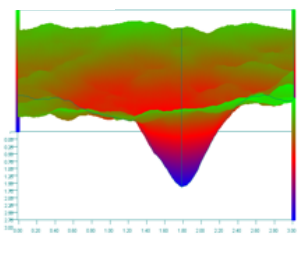

j)

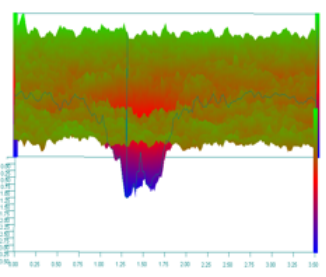

Figure 3: Representative profilometer scanned surfaces of ivory dentine after air-polishing for $5 \mathrm{~s}$ and 10s. (a, f) BiominF ${ }^{\circ},(\mathrm{b}, \mathrm{g})$ Sylc ${ }^{\circ}$ Blend, $(\mathrm{c}, \mathrm{h})$ sodium bicarbonate, (d, i) glycine, and (e, j) erythritol.

\section{Discussion}

Biomin $F^{\circ}$ is a novel bioactive glass that has the advantage in promoting remineralization and has a desensitizing effect by the formation of fluorapatite to occlude dentinal tubules. There is limited information regarding the safety of using this powder as a polishing powder for debridement on the dentine surface compared to other commercially available powders. A previous study showed that this powder was significantly less abrasive than either sodium bicarbonate or glycine [14] using a different type of handpiece. On the contrary, the main finding of the present study revealed that bioactive glasses (BiominF ${ }^{\circ}$ and Sylc Blend) were to be significantly more abrasive than the reference powders (sodium bicarbonate, glycine, and erythritol). Unlike the previous study, the present study also evaluated the powder output rate. Despite the small particle size of BiominF ${ }^{\circ}$, the greater damage observed on the dentine surface indicated that other factors may play a significant role in determining the abrasiveness of powders. It was shown that the rate of dentine loss increased with increasing exposure time $[9,15]$. The findings of this study also a showed deeper wear depth with increased application time ( $5 \mathrm{~s}$ vs $10 \mathrm{~s}$ ) in the BiominF ${ }^{\circ}$, Sylc Blend, and glycine powder.

Bioactive glasses were first developed as a bone replacement material [16] and has since expanded its application for regenerating dental hard tissue [17]. Its application has extended to being used as an abrasive agent for dental prophylaxis [13] air abrasion for caries removal $[18,19]$ and residual orthodontic adhesive removal [20]. The first large scale commercial use of a bioactive glass was for the treatment of dentine hypersensitivity. The addition of fluoride to bioactive glasses enables the formation of fluorapatite to occlude dentinal tubules, when in contact with oral fluids. Fluorapatite is more acid-resistant than carbonated hydroxyapatite [21] to an acidic attack. Fluorapatite is beneficial in the prevention of dental caries, enhancing remineralization, and treating dentine hypersensitivity.
A clinical trial reported that the use of bioactive glass toothpaste containing 5\% Fluoro-calcium phospho-silicate resulted in a more effective reduction of dentine hypersensitivity compared to arginine and calcium carbonate-based products [22]. The primary aim of using bioactive glass as an air polishing powder is to debride root surfaces simultaneously with occluding in dentinal tubules by depositing calcium phosphate ions onto the tooth surface. The use of bioactive glass with an air-polishing system has been demonstrated to be the most effective approach to create a dentine surface resistant to acid attack and reduce dentine permeability [12]. A clinical trial reported that this bioactive glass was more effective in the removal of extrinsic strain and offered a longer desensitizing effect compared to sodium bicarbonate [13]. The fact that this powder was more efficient in stain removal could be due to its greater powder density which may be a concern regarding the safety when applying the powder on the root dentine surface.

Sultan et al. (2019) investigated the use of bioactive glass, BiominF ${ }^{\circledR}$, on dentine surfaces and showed that this powder was more conservative in terms of abrasivity compared to either sodium bicarbonate or glycine powders. In the present study, a NSK's Prophy-Mate neo handpiece was used, instead of the Aqua Care air abrasion system used in a previous study, to facilitate the powder output rate determination by adding a pyrogenic silica as a flow aid. The results of the present study showed that both bioactive glasses, Sylc Blend and BiominF" were significantly more aggressive compared to the other powders. A significant amount of dentine loss, up to $250 \mu \mathrm{m}$, was created in a relatively short application time, thus great caution must be exercised before using these powders on dentine surfaces. Considering that the thickness of cementum around the cervical region ranged from 50 to $200 \mu \mathrm{m}$ [23], the repeated application of these powders should be avoided. Comparing the findings of the present study, the amount of root surface loss due to the bioactive glass powders were comparable to those root surfaces 
instrumented with curettes when applying 12 working stokes with an applied force of 500-1000 $\mathrm{p}$ [2]. On the other hand, the application of a high sodium content fluoride-containing bioactive glass in air abrasion on the enamel surfaces was showed to be effective in the removal of residual orthodontic adhesive without causing significant enamel damage when compared to $45 \mathrm{~S} 5$ (Sylc ) bioactive glass and a tungsten carbide bur. This was in all probability due to the hardness of the glass which was harder than the orthodontic adhesive but softer than the enamel surface. Apatite formation from BiominF ${ }^{\circ}$, which occurs earlier than $45 \mathrm{~S} 5$ (Sylc), provided an additional benefit in promoting enamel remineralization [20].

Sodium bicarbonate, glycine, and erythritol were shown to be much more conservative powders when applying to the dentine surface without causing significant differences. In this present study, sodium bicarbonate produced only slightly deeper wear depth compared with glycine and erythritol. This contradicts a previous study showing that glycine powder resulted in significantly less substance loss when compared with sodium bicarbonate [8]. Also, the finding of this study showed no significant difference in the wear depth between glycine and erythritol, which is in accordance with a previous study indicating that these powders have a similar smaller surface-damaging potential [24].

The abrasiveness of an air-polishing application is determined by various factors including particle size and particle size distribution [25], the shape of the particles [26], hardness of the particle forming the powder, power and water setting, working distance, application time [9]. It was shown that the abrasivity effect of air abrasion is correlated with the D90 particle size in the distribution [27]. Despite the smaller particle size of BiominF ${ }^{\circ}$, the greatest wear depth was produced by BiominF ${ }^{\circ}$. This could be explained by the greater hardness of bioactive glasses compared to the reference powders. Mohs hardness index of bioactive glasses are significantly higher than those of sodium bicarbonate, glycine, and erythritol [28]. The Vickers hardness of BiominF ${ }^{\circ}$ and Sylc was $4.5 \mathrm{GPa}$ and $4.63 \mathrm{GPa}$, respectively [20].

It has been demonstrated that a mean particle size below $12 \mu \mathrm{m}$ would have limited flowability due to greater Van der Waals forces between particles that resulted in the tendency of particles to stick together rather than flow freely from the handpiece [29]. Hydrophobic fumed silica (Aerosil 974), which has an anti-caking property, was added to BiominF ${ }^{\circ}$ to improve the flowability. Aerosil 974 coated the surface of small particles, creating space between them thus allowing particles to flow freely. The powder output rate of BiominF with the addition of $1 \%$ by weight of Aerosil 974 resulted in a comparable flowability to glycine and erythritol and significantly greater than Sylc Blend and sodium bicarbonate. The low standard deviation of powder output may indicate that BiominF ${ }^{\circ}$ could transport reproducibly and reliably. A previous study showed that BiominF is less abrasive than Sylc ${ }^{\circ}$ of similar particle size [27]. It is important to note that in this study, no information regarding powder output rate was provided [14]. In the present study, BiominF ${ }^{\circ}$ and Sylc ${ }^{\circ}$ blend showed similar abrasiveness as represented in comparable wear depth despite the significantly higher powder output rate of BiominF ${ }^{\circ}$. The greater powder output rate of BiominF $\mathrm{F}^{\circ}$ may result in an increased kinetic energy and damage transferred to the tooth surface.
Various tooth substitute materials have been utilized to reduce variability arising from the different tooth samples. The enamel analogue, Macor, was used as a substrate in previous air-abrasion studies to minimize unwanted physical variables [27,30]. Ivory dentine was introduced for evaluating surface changes due to airpolishing application as the model offered a reduction in the variation compared to human dentine by providing a large flat surface area ideal for laboratory investigation $[14,18]$. A slightly lower hydroxyapatite content has been observed for ivory dentine compared to human dentine resulting in a lower bending strength. Nevertheless, the size and shape of dentinal tubules of ivory dentine and its modulus and presumably its hardness are comparable to that of human dentine [31]. No direct comparison of ivory dentine and the tooth surface for air polishing application was assessed in the present study which may limit extrapolation of any findings to human dentine.

A non-contact optical profilometer is an optical device utilizing either laser or white light to quantify the mineral loss of hard tissue and measure the surface roughhouses and functions by comparing different height differences using a spectrometer. White light profilometer, used in the present study, is a non-invasive method to analyze the surface topography without any physical contact with the sample [32]. This technique was shown to provide a reliable method for quantifying surface loss with a similar level of precision compared to other measuring methods [33].

The present study provides a comprehensive investigation regarding the abrasiveness of available powders. A previous study only assessed the effect of different commercially available powders on enamel surfaces only [34].

It is important to note that comparison of the findings from this present study to other studies is difficult due to differences in the experimental protocols. For instance, water was not added in the study because water films coated on the surface may dampen the impact of the abrasive particles [35] as well as influence the wear depth [9]. A standardized experimental protocol, therefore, needs to be established when evaluating the abrasiveness of air polishing powders.

Further improvement in bioactive glass as a potential air polishing powders on the root surface is still required. It was shown that increasing $\mathrm{Na}_{2} \mathrm{O}$ can cause a pronounced decrease in bioactive glass hardness [26]. The question as to whether usingan air polishing device with a reduced pressure would be beneficial in reducing the abrasivity of bioactive glass powders should also be investigated. A previous study showed that the debridement efficacy of a glycine powder after $5 \mathrm{~s}$ application as represented by a stain-free area was only observed in around $45 \%$ of periodontal pockets with various depths [36]. It is still unknown if a more abrasive powder would result in more effective biofilm removal, and whether or not the presence of the dental biofilm could limit any potential damage to the dentine. The effect on the soft tissue a bioactive glass powder should also be further investigated.

\section{Conclusion}

Bioactive glasses (BiominF ${ }^{\circledR}$ and Sylc Blend) were significantly more abrasive than sodium bicarbonate, glycine, and erythritol powders. The abrasiveness of bioactive glasses should be reduced to 
Kitichai Janaphan (2021) In Vitro Evaluation of the Abrasiveness of Novel Bioactive Glass Powders (BiominF®) on Ivory Dentine in Air Polishing

Procedures Compared to Selected Reference Powders

minimize the loss of root dentine to take advantage of the desensitizing effect and promotion of remineralization of these glasses. Further studies are required to improve the powder characteristics for a safe and effective mean to debride root surfaces.

\section{Funding}

KJ was awarded a financial sponsorship by the Thai Government to study for a DClinDent Degree in Periodontology at Queen Mary University of London which included a research component and report.

\section{Reference}

1. Papapanou PN, Sanz M, Buduneli N, Dietrich T, Feres M, Fine DH, Flemmig TF, Garcia R, Giannobile WV and Graziani F (2018) Periodontitis: Consensus report of workgroup 2 of the 2017 World Workshop on the Classification of Periodontal and Peri-Implant Diseases and Conditions. Journal of Periodontology 89: S173-S182. [crossref]

2. Ritz L, Hefti AF and Rateitschak KH (1991) An in vitro investigation on the loss of root substance in scaling with various instruments. Journal of Clinical Periodontology 18: 643-647. [crossref]

3. Zappa U, Smith B, Simona C, Graf H, Case D and Kim W (1991) Root substance removal by scaling and root planing. Journal of Periodontology 62: 750-754. [crossref]

4. Moëne R, Décaillet F, Andersen E and Mombelli A (2010) Subgingival plaque removal using a new air-polishing device. Journal of Periodontology 81: 79-88. [crossref]

5. Wennström JL, Dahlén G and Ramberg P (2011) Subgingival debridement of periodontal pockets by air polishing in comparison with ultrasonic instrumentation during maintenance therapy. Journal of Clinical Periodontology 38: 820-827. [crossref]

6. Müller N, Moëne R, Cancela JA and Mombelli A (2014) Subgingival air-polishing with erythritol during periodontal maintenance: Randomized clinical trial of twelve months. Journal of Clinical Periodontology 41: 883-889. [crossref]

7. Cosgarea R, Jepsen S, Fimmers R, Bodea A, Eick S and Sculean A (2021) Clinical outcomes following periodontal surgery and root surface decontamination by erythritol-based air polishing. A randomized, controlled, clinical pilot study. Clinical Oral Investigations 25: 627-635. [crossref]

8. Petersilka GJ, Bell M, Häberlein I, Mehl A, Hickel R and Flemmig TF (2003) In vitro evaluation of novel low abrasive air polishing powders. Journal of Clinical Periodontology 30: 9-13. [crossref]

9. Petersilka GJ, Bell M, Mehl A, Hickel R and Flemmig TF (2003) Root defects following air polishing: An in vitro study on the effects of working parameters. Journal of Clinical Periodontology 30: 165-170. [crossref]

10. Petersilka GJ, Steinmann D, Häberlein I, Heinecke A and Flemmig TF (2003) Subgingival plaque removal in buccal and lingual sites using a novel low abrasive air-polishing powder. Journal of Clinical Periodontology 30: 328-333. [crossref]

11. Bühler J, Amato M, Weiger R and Walter C (2016) A systematic review on the effects of air polishing devices on oral tissues. International Journal of Dental Hygiene 14: 15-28. [crossref]

12. Sauro S, Watson TF and Thompson I (2010) Dentine desensitization induced by prophylactic and air-polishing procedures: an in vitro dentine permeability and confocal microscopy study. Journal of Dentistry 38: 411-422.

13. Banerjee A, Hajatdoost-Sani M, Farrell S and Thompson I (2010) A clinical evaluation and comparison of bioactive glass and sodium bicarbonate air-polishing powders. Journal of Dentistry 38: 475-479. [crossref]

14. Sultan D, Hill R and Gillam D (2019) The use of a Novel Bioactive Glass in Air Polishing. Adv Dent \& Oral Health.

15. Galloway S and Pashley DH (1987) Rate of removal of root structure by the use of the Prophy-Jet device. Journal of Periodontology 58: 464-469. [crossref]

16. Hench LL and Paschall H (1973) Direct chemical bond of bioactive glass-ceramic materials to bone and muscle. Journal of Biomedical Materials Research 7: 25-42. [crossref]

17. Brauer DS (2015) Bioactive glasses-structure and properties. Angewandte Chemie International Edition 54: 4160-4181. [crossref]
18. Tan MH, Hill RG and Anderson P (2015) Comparing the air abrasion cutting efficacy of dentine using a fluoride-containing bioactive glass versus an alumina abrasive: An in vitro study. International Journal of Dentistry 2015.

19. Banerjee A, Pabari H, Paolinelis G, Thompson ID and Watson TF (2011) An in vitro evaluation of selective demineralised enamel removal using bio-active glass air abrasion. Clinical Oral Investigations 15: 895-900. [crossref]

20. Taha AA, Hill RG, Fleming PS and Patel MP (2018) Development of a novel bioactive glass for air-abrasion to selectively remove orthodontic adhesives. Clinical Oral Investigations 22: 1839-1849. [crossref]

21. Brauer DS, Karpukhina N, O'Donnell MD, Law RV and Hill RG (2010) Fluoridecontaining bioactive glasses: effect of glass design and structure on degradation, $\mathrm{pH}$ and apatite formation in simulated body fluid. Acta Biomaterialia 6: 3275-3282.

22. Patel VR, Shettar L, Thakur S, Gillam D and Kamala DN (2019) A randomised clinical trial on the efficacy of $5 \%$ fluorocalcium phosphosilicate-containing novel bioactive glass toothpaste. Journal of Oral Rehabilitation 46: 1121-1126. [crossref]

23. Yamamoto T, Hasegawa T, Yamamoto T, Hongo H and Amizuka N (2016) Histology of human cementum: Its structure, function, and development. Japanese Dental Science Review 52: 63-74. [crossref]

24. Janiszewska-Olszowska J, Drozdzik A, Tandecka K and Grocholewicz K (2020) Effect of air-polishing on surface roughness of composite dental restorative material-comparison of three different air-polishing powders. BMC Oral Health 20: 1-7. [crossref]

25. Tada K, Kakuta K, Ogura H and Sato S (2010) Effect of particle diameter on air polishing of dentin surfaces. Odontology 98: 31-36. [crossref]

26. Farooq I, Tylkowski M, Müller S, Janicki T, Brauer DS and Hill RG (2013) Influence of sodium content on the properties of bioactive glasses for use in air abrasion. Biomedical Materials 8: 065008. [crossref]

27. Masood H, Gillam D and Hill R (2020) The Effect of Bioactive Glasses in Air Abrasion Procedures. Journal of Orthodontics and Craniofacial Research.

28. Barnes CM, Covey D, Watanabe H, Simetich B, Schulte JR and Chen H (2014) An in vitro comparison of the effects of various air polishing powders on enamel and selected esthetic restorative materials. J Clin Dent 25: 76-87. [crossref]

29. Haeberlein IR, Schmid B and Pfarrer AM (2016) Powder composition for air polishing the surface of hard dental tissue. U.S. Patent 9,358,185. [crossref]

30. Paolinelis G, Banerjee A and Watson TF (2009) An in vitro evaluation of the efficiency of an air-abrasion system using helium as a propellant. Dental Materials 25: 1442-1445. [crossref]

31. Liaqat S, Aljabo A, Khan MA, Nuba HB, Bozec L, Ashley P and Young A (2015) Characterization of dentine to assess bond strength of dental composites. Materials 8: 2110-2126. [crossref]

32. Baysan A, Sleibi A, Ozel B and Anderson P (2018) The quantification of surface roughness on root caries using Noncontact Optical Profilometry-An in vitro study. Lasers in Dental Science 2: 229-237. [crossref]

33. Paepegaey A-M, Barker ML, Bartlett DW, Mistry M, West NX, Hellin N, Brown LJ and Bellamy PG (2013) Measuring enamel erosion: a comparative study of contact profilometry, non-contact profilometry and confocal laser scanning microscopy. Dental Materials 29: 1265-1272. [crossref]

34. Sinjari B, D’Addazio G, Bozzi M, Santilli M, Traini T, Murmura G and Caputi S (2019) SEM Analysis of enamel abrasion after air polishing treatment with erythritol, glycine and sodium bicarbonate. Coatings 9: 549. [crossref]

35. Clark HM and Burmeister L (1992) The influence of the squeeze film on particle impact velocities in erosion. International Journal of Impact Engineering 12: 415-426. [crossref]

36. Flemmig TF, Hetzel M, Topoll H, Gerss J, Haeberlein I and Petersilka G (2007) Subgingival debridement efficacy of glycine powder air polishing. Journal of Periodontology 78: 1002-1010. [crossref]

\section{Citation:}

Janaphan K, Hill RG, Gillam DG (2021) In Vitro Evaluation of the Abrasiveness of Novel Bioactive Glass Powders (BiominF ${ }^{\circledast}$ ) on Ivory Dentine in Air Polishing Procedures Compared to Selected Reference Powders. J Dent Maxillofacial Res Volume 4(2): 1-6. 